\title{
"MY DEAR DE MADARIAGA". CORRESPONDENCIA ENTRE MADARIAGA E EDEN EN 1936 EN PROL DUNHA PAZ NEGOCIADA NA GUERRA CIVIL ESPAÑOLA ${ }^{1}$
}

\section{"MY DEAR DE MADARIAGA". CORRESPONDENCE MADARIAGA-EDEN IN 1936 TO PROMOTE A NEGOTIATED PEACE IN THE SPANISH CIVIL WAR}

\author{
ANTÓN M. PAZOS \\ CSIC-Xunta de Galicia \\ Instituto de Estudos Galegos "Padre Sarmiento"
}

\begin{abstract}
Resumen
Entre los nuevos estudios sobre la guerra civil española destacan las dedicadas a los hombres de la tercera España, que buscaron caminos de paz sin esperar el resultado de la contienda. Entre esos sobresale Salvador de Madariaga, del que recogemos aquí su correspondencia en 1936 con el ministro de Exteriores británico Anthony Eden, que se conserva en el fondo Madariaga del Instituto José Cornide de Estudios Coruñeses. Las propuestas de Madariaga, como otros intentos de paz anteriores al $1 \mathrm{de}$ abril de 1939, cuyo 70 aniversario se cumple este año, resultaron fallidos, tanto por la postura de la diplomacia europea, especialmente británica, como por el enfrentamiento de concepciones antitéticas y radicales que supuso la guerra, que no dejó espacio para la mediación y el acuerdo entre partes.
\end{abstract}

\section{Palabras clave}

Salvador de Madariaga. Anthony Eden. Cranborne. Gandhi. Guerra civil española. 1936-1939. 1936. Comité de no intervención. Franco. Entreguerras. España. Europa. II Guerra mundial.

\begin{abstract}
Among the new studies on the Spanish civil war we can highlight the works devoted to those men involved in the third Spain, who were sought ways of peace, without expecting the outcome of the war. Salvador de Madariaga was one of the most distinguished men of the third Spain. Here we transcribe his correspondence with the British Secretary of State for Foreign Affairs Anthony Eden. These documents, together with the entire legacy of Madariaga, are kept in the Instituto José Cornide de Estudios Coruñeses. The proposals of Madariaga, like other peace attempts prior to April 1, 1939, were unsuccessful. As we can see in these letters, British Diplomacy preferred to keep a noninterventionist approach to the war instead of the mediation as was proposed by Madariaga.
\end{abstract}

\section{Keywords}

Salvador de Madariaga. Anthony Eden. Cranborne. Gandhi. Spanish civil war. 19361939. 1936. Non-Intervention Committee. Franco. Spain. Europe. World War II.

\footnotetext{
${ }^{1}$ Entregado 01.03.2009.
} 
Nos últimos anos apréciase, xunto ao paradoxal contrapunto da polémica nos medios de comunicación, unha maior obxectividade ${ }^{2}$ nos estudos sobre a guerra civil, en parte grazas á recente apertura ${ }^{3}$ ou edición ${ }^{4}$ de novos arquivos ou á renovación dos temas de investigación. Xúntanse ambas as dúas características en recentes publicacións sobre aspectos internacionais da guerra civil, que, ao tempo que utilizan arquivos recentemente dispoñibles, reavivan os traballos clásicos de tipo diplomático con novos intereses e enfoques, dende a repercusión da guerra civil na opinión pública ${ }^{5}$ ao labor humanitario dos corpos diplomáticos nun e outro bando ${ }^{6}$.

Dentro destes novos estudos vaise dando cada vez máis protagonismo aos españois non aliñados nin coa revolución nin coa rebelión, cidadáns que se deu en clasificar como dunha terceira España pero que, realmente, estiveron en ambos os dous bandos: foron liberais entre os republicanos ou moderados entre os franquistas sen lograr influencia nin acomodo en ningún dos grupos en contenda, algo imposible nunha sociedade tan polarizada como a da guerra civil. Julián Marías, do que acaban de publicarse ${ }^{7}$ os seus artigos no $\mathrm{ABC}$ republicano durante as últimas

2 Referíndose á apertura, recente en moitos casos, de arquivos sobre a guerra civil, recorda Raguer como "a mesura que els historiadors han tingut acces als arxius publics i privats, la historia de la guerra civil ha guanyat en objectivitat" (RAGUER i SUÑER, Hilari, Arxiu de l'esglesia catalana durant la Guerra Civil, juliol-desembre 1936, Barcelona 2003, p. 5).

${ }^{3}$ Quizais o máis sinalado sexa o da Nunciatura Madrid no Arquivo Secreto Vaticano, para o pontificado de Pío XI, que deu lugar xa a numerosas publicacións, algunhas rechamantemente prematuras con respecto á data de apertura, pero que ofrecen puntos de vista novos sobre un dos asuntos máis controvertidos da guerra como é a participación da xerarquía católica no conflito.

${ }^{4}$ Entre eles o Archivo Gomá: ANDRÉS-GALLEGO José - PAZOS, Antón M. (eds.), Archivo Gomá: Documentos de la Guerra Civil, Madrid, 2001-2009, 12 vols.

5 Como autor xa clásico, compre destacar a Tom Buchanan que traballou excelentemente o impacto da guerra española no mundo británico en numerosos libros e dende varios puntos de vista. Un exemplo entre os máis recentes pode ser Hugo GARCÍA FERNÁNDEZ que, na sua tese Mentiras necesarias: la batalla por la opinión británica durante la guerra civil, Madrid 2008, presenta as posturas de ambos os dous bandos para captar a opinión pública inglesa, sen que quede claro quén gañou esa batalla, nin sequera, se os esforzos propagandísticos chegaron realmente a calar no conxunto da poboación. De feito, os comportamentos gubernamentais, e serve para os textos que aquí presentamos, ofrecen unha visión de aséptica diplomacia acorde coa prudente acollida que deron no Foreing Office ás propostas iniciais de Madariaga.

6 Un exemplo significativo pode ser Antonio Manuel MORAL RONCAL, Diplomacia, humanitarismo y espionaje en la Guerra Civil española, Madrid 2008, que recolle parte dos seus traballos anteriores sobre o uso do asilo diplomático durante a guerra, ofrecendo unha visión de conxunto moi axustada e reflectindo, ademais, o renovado interese pola guerra civil en novos investigadores de países do centro e do leste de Europa.

7 Así o presenta Helio CARPINTERO, dende o título do seu estudo: Una voz de la "tercera España” Julián Marías, 1939, Madrid 2007, ao reproducir e comentar os artigos de Marías no ABC madrileño no último mes da guerra civil, considerando que Marías é dos que fixo un "importante esfuerzo que aspiraba a dejar la guerra atrás y echar a andar hacia adelante en verdadera paz" (p. 147). 
semanas da guerra, sería un bo exemplo destas "voces da terceira España" que buscaron un acordo imposible entre os contendentes. Ou polo menos, se non un acordo, o máis parecido a unha concordia entre inimigos unidos por lazos de sangue e terra: aí habería que incluír os distintos intentos de mediación que se intentaron para parar a guerra, sempre infrutuosos, pero tamén sempre presentes dende o verán do 36 ata os últimos días de combate ${ }^{8}$. Quizais, con matices, tamén poderían situarse neste territorio os chamamentos de paz e concordia entre compatriotas, presentes así mesmo dende o principio da guerra. Estes chamamentos, ademais, chegaron non só desa hipotética e reducida terceira España senón das outras dúas, maioritarias e enfrontadas a morte, e iso dende as autoridades republicanas ${ }^{9}$ ata as aliñadas no bando contrario ${ }^{10}$. Aínda que tamén moitos destes protagonistas desexosos -con

\footnotetext{
${ }^{8}$ A propia diplomacia vaticana intentou unha vez máis en 1937 unha mediación, a partir dos contactos tidos por mons. Pizzardo con ocasión da súa viaxe á coroación do rei Jorge VI, onde, curiosamente, o protocolo o fixo compartir mesa e mantel con Julián Besteiro, representante da República española, que levóu a Eden unha mensaxe moi na liña de Madariga, de cara a que Inglaterra intervise activamente para forzar a paz entre os bandos combatentes. O propio Pizzardo propúxollo ao card. Gomá, co que se reuníu en Lourdes, proposta que Gomá rexeitou por irreal e improcedente. É unha mostra máis dos matices presentes en moitos dos actores da guerra civil, onde coexiste o rexeitamento a toda posible idea de pacto coa ética do perdón e a reconciliación. Sobre os intentos de mediación en maio de 1937 pode verse o plan de actuación previsto en Archivo Gomá, Documento 5-366 e a resposta de Gomá en Documento 5-388. Os intentos de mediación do outono de 1938, en Archivo Gomá, Documento 12-31 coa resposta de Gomá a Serrano Suñer sobre a imposibilidade de que unha mediación permitise a paz e a unidade dos españois, tal como se formulaba neses momentos.

${ }^{9}$ Pode servir como paradigma o tan coñecido -e longo- discurso de Azaña en Barcelona propoñendo a afortunada e programática triloxía "Paz, piedad y perdón", recollido na monumental edición de Santos JULIÁ: Manuel Azaña. Obras completas, 6, Julio de 1936-agosto de 1940, Madrid 2008, "Discurso en el Ayuntamiento de Barcelona. Pronunciado el 18 de julio de 1938", pp. 168-181.

${ }^{10}$ Abonde citar ao bispo de Pamplona, Marcelino Olaechea na súa homilía "Ni una gota de sangre de venganza", con motivo dunha concentración de Acción Católica, aos poucos días de terse producido o asasinato en Tafalla de 51 presos no cárcere local, "sacados" vengativamente pola multitude ao final do enterro dun oficial do pobo morto na fronte. A homilía foi publicada co título "La voz del Prelado. Ni una gota de sangre de venganza", no Boletín Oficial Eclesiástico del Obispado de Pamplona, 76, Núm. 1.839 (1936) 429-431, con obriga de ser lida polos párrocos en todas as misas dominicais de Navarra. E rematada a guerra o propio primado da Igrexa española, e indubidable partidario de Franco, o cardeal Isidro Gomá escribiu a súa pastoral "Lecciones de la guerra y deberes de la paz" na que propugnaba tamén unha paz das conciencias e unha actitude de perdón e esquecemento. A pastoral, aínda que difundida nos boletíns eclesiásticos, foi prohibida pola censura, con gran perplexidade e malestar por parte do cardeal, que protestou, moi doído, ante Franco. Os textos fundamentais de ambos os dous escritos con expresións como “¡Que nadie sufra! ¡Que se perdone a todos!” de Olaechea ou "tenemos el deber de perdonar y de amar a los que han sido nuestro enemigos" de Gomá, os recollemos en ANDRÉS-GALLEGO, José - PAZOS, Antón M., La Iglesia en la España Contemporánea, II, Madrid, 1999, pp. 21-22. Faría falta un estudo semántico dos discursos e homilías de paz, piedade e perdón, ao estilo dos que se fixeron por varios autores cos discursos máis claramente belicosos.
} 
restricións- de paz e reconciliación tiveron claro que non habería posibilidade de volver a unha situación parecida á de preguerra precisamente porque o que se estaba a librar era unha loita ideolóxica dende posicións antitéticas ${ }^{11}$.

Salvador de Madariaga foi á vez un home da terceira España ${ }^{12}$ e un pacificador: foi un home liberal nun ámbito radicalizado e un activo promotor de propostas de

${ }^{11}$ Como exemplo desa percepción de loita ideolóxica serve perfectamente a postura recente dun dos poucos protagonistas aínda vivos da época, Santiago Carrillo, que reprocha a Indalecio Prieto a súa tendencia á negociación e o seu carácter republicano neutral: "Prieto era un hombre de indudable talento. Su principal mérito en ese período fue que, aun siendo profundamente escéptico sobre las posibilidades de victoria de la Republica, no hurtaría el cuerpo a las responsabilidades políticas. Pero entregar la dirección militar a un hombre que carecía de confianza en la victoria no era la decisión más adecuada en plena guerra. A esta falla, Prieto añadía lo que constituía otra, particularmente preocupante, dadas las circunstancias del Ejército Popular. Prieto era muy anticomunista, tenía la intención de convertir el Ejército en algo asépticamente republicano, lo que chocaba con el carácter que tenía aquella guerra, con un contenido social y popular profundo, que era lo que proporcionaba a las tropas republicanas una capacidad de combate y un espíritu de sacrificio indispensables para compensar el desequilibrio de medios existentes entre la República y el Ejército rebelde, mucho mejor dotado de material. De hecho, los comunistas estaban preparados política e ideológicamente mucho mejor que otros partidos para librar una guerra popular, pues sin ser los únicos que luchaban, eran colectivamente los mejor preparados para insuflar en las tropas su moral de resistencia y de victoria". (CARRILlO, Santiago, Dolores Ibarruri. Pasionaria, Una fuerza de la naturaleza, Barcelona 2008, pp. 121-122).

12 Aínda que non todos o clasifican tan favorablemente: "Madariaga, incapaz de comprender el significado del advenimiento de la civilización de masas, antisocialista y antimarxista, encarna el ocaso de los valores de la vieja sociedad liberal decimonónica" (GONZÁLEZ CUEVAS, Pedro Carlos, "El pensamiento político de Salvador de Madariaga", Hispania, 49 (1989) 307). Tampouco a "terceira España" era tan ben vista na guerra: "En España dos bandos feroces tratan de destruirse. Ninguno puede dominar al otro. Cuando se reconozca así y se acabe la guerra, los que se mantienen lejos de ella y reprueban a los dos bandos, se encargarán de gobernar al país. No disimulo mi horror por tantas cosas como suceden, acá y allá. Al oír esas vanidades, siento que me penetra el espíritu intransigente del miliciano" (AZAÑA, Manuel, La velada en Benicarló. Diálogo sobre la guerra de España, Buenos Aires [1939], p. 21). E quizais aí entraría tamén Madariaga, trasuntado no personaxe que critica un dos contertulios de Benicarló ó falar dos da terceira España: "Que son finos, superiores a nosotros, verdaderos cafres que aguantamos los bombardeos, se les nota cuando por accidente vienen a España. Uno estuvo en Valencia cuatro días. Muy enojado porque el gobierno no se apresura a editarle su obra sobre Recesvinto... ¡Ya ven ustedes, Recesvinto! Me habló del Foreing Office, del Quaid'Orsay, del Gentlemens' agreement, del Covenant, de la seguridad colectiva, de los asentamientos de campesinos asirios, de la Conferencia de los Nueve, del Comité de los Veintitrés... Precaviéndose contra un reproche que nunca pensé hacerle, afectaba una distinción lánguida. Leía en sus ojos cierta protección distante, compasiva. Aquella noche sufrimos un ataque aéreo. Mucho ruido. Algunos muertos. El hombre se presentó en mi casa a pedirme que obtuviese de Prieto un permiso para salir en el primer avión. No le dí de bofetadas. Ha repasado los Pirineos. Mis carcajadas lo acompañan" (Ibid., 22-23). Dende logo a presentación do personaxe coincide coa opinión de Azaña sobre "el pedante de Madariaga" (Cfr. "Diarios. La Pobleta 1937", en Ibid., 322). A Velada en Benicarló, que citamos pola edición orixinal, recóllese tamén en JULIÁ, Santos, Manuel Azaña. Obras completas, 6, 33-92. 
mediación ao longo de toda a guerra. $\mathrm{O}$ seu arquivo particular ${ }^{13}$, conservado na Coruña, custodia numerosos detalles da súa actividade pública e privada. Neste ano en que se cumpren os 70 anos do final da guerra civil, paga a pena recordar as súas posturas ante o conflito e recoller o testemuño da súa opinión e -sobre todo- da opinión que, do modo máis obxectivo posible segundo el, quixo transmitir aos seus contactos políticos para comprometelos en actuacións que puidesen parar a guerra. Nesta correspondencia recóllese a súa coñecida postura sobre as responsabilidades dos distintos partidos de esquerdas ${ }^{14}$ no fracaso da república, pero queda claro ao mesmo tempo non só o seu rexeitamento do réxime que impoñerían os militares sublevados se gañaban a guerra, que cualifica de militar-clerical ${ }^{15}$, senón a necesidade, que dá por suposta, de apartar a Franco do goberno ${ }^{16}$.

Quizais o máis importante dos correspondentes de Madariaga, e o único ao que nos imos referir nas cartas aquí recollidas, é Anthony Eden, co que o uniu unha cordial relación. Se é certo que, segundo a valoración de Azaña ${ }^{17}$, a primeira das cau-

${ }^{13}$ Recentemente publicouse o inventario polo Instituto José Cornide de Estudios Coruñeses: FERNÁNDEZ-ALBALAT y LOIS, Andrés, Salvador de Madariaga: inventario de los fondos documentales, La Coruña 2008. O PDF do inventario on line en http://www.ijcec.es/dbimages/File/Libro\%20Madariaga web.pdf (1.3.2009). Unha síntese biográfica con amplas referencias ó arquivo e algunhas reproducións de documentos en LÓPEZ PRADO, Antonio, Síntesis biográfica de Don Salvador de Madariga, La Coruña 1993. A primeira correspondencia con Madariaga eu MARTÍNEZ-BARBEITO, Carlos "El Archivo de Madariaga en La Coruña" XXII (1986) 177-193 e VELO PENSADO, Ismael, "Fondos de Madariaga. Clasificación y catalogación" XXIII (1987) 253-279, que foi quen fio a primeira catalogación dos fondos, que recolle no artigo pero que xa non teñen que ver coa clasificación actual.

${ }^{14}$ Algo que deixou claro en numerosos escritos, ata o punto de que Prieto puido escribir que lendo a Madariaga parecería xustificado o levantamento militar. Xustamente a realidade é a contraria, xa que unha das primeiras cousas que Madariaga quer deixar claro nas súas explicacións a Eden sobre a guerra civil española é que a situación de ingobernabilidade dos meses da Frente Popular "podería explicar pero de ningunha maneira xustificaría a rebelión militar" (Cfr. Madariaga a Eden, 18.VIII. 1936, Documento 1).

15 Madariaga a Eden, 18.VIII.1936, Documento 1.

${ }^{16}$ Ao formular a Eden a necesidade de contar cos alemáns en calquera intento global de mediación xustifícao precisamente porque un dos puntos esenciais sería a caída de Franco, algo que era necesario negociar cos alemáns para que o entendesen e apoiasen: "You cannot expect the German government to drop Franco altogether without their knowing who is going to govern Spain when Franco is dropped and the war is over" (Cfr. Madariaga a Eden, 30.XII.1936, Documento 7).

${ }^{17}$ Dende o principio de guerra viuno así. En palabras do seu alter ego na Velada, o ex-ministro Garcés, dí: "Enumerados por orden de su importancia, de mayor a menor, los enemigos de la República son: la política franco-inglesa; la intervención armada de Italia y Alemania; los desmanes, la indisciplina y los fines subalternos que han menoscabado la reputación de la República y la autoridad del Gobierno; por último, las fuerzas propias de los rebeldes. ¿Dónde estarían ahora los sublevados de julio, si las otras tres causas, singularmente la primera, no hubiesen obrado a su favor?" (AZAÑA, Manuel, La velada en Benicarló, 65). E diretamente, sen personaxe interposto, consideraba xa en 1937 que "nuestro mayor enemigo hasta ahora ha sido el gobierno británico" ("Diarios. La Pobleta 1937", en Manuel Azaña. Obras completas, 6, p. 323). 
sas da derrota republicana foi a postura inglesa de non intervención, certamente Madariaga propuxo as súas xestións de paz ao interlocutor máis influente de entre todas as forzas que podían intervir no conflito español. Tamén dende o principio formulou que a postura de non intervención, preconizada por Gran Bretaña, debía estar necesariamente vinculada a unha actitude igualmente decidida a favor da mediación.

O obxectivo final de Madariaga -claramente desenvolvido nas cartas que aquí recollemos- foi establecer un acordo entre as partes, que rematara a guerra e, ao mesmo tempo, puidese servir de punto de partida para construír unha España postbélica, allea en certo modo aos enfrontamentos feroces dos anos trinta, república incluída. Dende o seu punto de vista, Madariaga repartiu a responsabilidade entre todas as partes en conflito, partindo de que a propaganda ao uso non era aplicable á realidade. Deixou claro dende o primeiro momento, cando aínda non se sabía cál podería ser o bando vencedor, ou mesmo se dudaba de se algún puidese selo de xeito claro, que non era unha guerra entre legalidade e insurrección ou entre democracia e totalitarismo, xa que ambas as dúas partes estaban contaminadas polos totalitarismos e a desaparición da democracia:

"Non estamos ante unha guerra entre legalidade e ilegalidade xa que, dende as últimas eleccións, os dous ou tres elementos de mais peso na Fronte Popular que son indiferentes -ou mesmo contrarios-á Constitución levaron a cabo políticas arbitrarias e agresivas que o goberno liberal demócrata foi incapaz de controlar. Evidentemente, estas políticas extra-constitucionais disparáronse dende que estalou a rebelión"18.

Entre eses partidos anticonstitucionais incontrolados -e incontrolables polo goberno- situaba en primeiro lugar aos anarcosindicalistas, seguidos moi de preto polos comunistas e socialistas, o que facía insostible -como formulaba outro dos tópicos da propaganda ao uso- que se tratase dunha guerra entre demócratas e totalitarios:

"Non é ésta unha guerra da liberdade e a democracia contra a tiranía xa que, aínda que o Goberno é sinceramente liberal-democrático está controlado por socialistas, comunistas e, sobre todo, anarcosindicalistas que deliberadamente buscan o establecemento de réximes que son, en moitos aspectos, incompatibles coa liberdade e a democracia, de modo que ningún dos dous bandos pode erixirse en representante da liberdade e a democracia"19.

Máis aínda, considerar a guerra de España como unha loita entre o fascismo e a democracia víao como "unha tráxica falsa interpretación que podería contribuír a unha

\footnotetext{
${ }_{18}$ Madariaga a Eden, 18.VIII.1936, Documento 1.

${ }^{19}$ Madariaga a Eden, 18.VIII.1936, Documento 1.
} 
guerra europea"20. En xeral Madariaga, aínda que pon como principais inimigos da democracia ós comunistas e ós anarquistas, non deixa de recoñecer o carácter cando menos dubidosamente democráctico dos socialistas e a gran parte de responsabilidade que tiveron na crise do sistema republicano. De feito, nunha das súas propostas negociadoras, ao suxerir como grupo mediador ós tres presidentes das cortes republicanas, refírese a Besteiro como un dos poucos socialistas libres de responsabilidade:

"Besteiro, presidente das primeiras Cortes republicanas é un socialista altamente respectado, cabeza da tendencia moderada dentro do partido. Esta circunstancia fixo que o mantivesen marxinado nos últimos tres anos, pero convérteo, por outra parte, no único socialista que pode considerarse libre de toda responsabilidade" 21 .

Así formulada a cuestión, Madariaga propuxo, dende os primeiros meses da guerra, o que lle pareceu máis realista ${ }^{22}$ e menos daniño para os españois. Primeiro parar a guerra: "por razóns humanitarias é necesario poñer fin a esta horrible carnizaría" 23 . Logo, tras frear a matanza, precisábase negociar unha saída concertada -e aceptada polas grandes potencias- para o futuro do país, que non vía claro dende o punto de vista democrático gañase quen gañase:

"Nos dous bandos mestúranse tamén as posicións encontradas e, en canto se sintan libres da presión do inimigo común lanzaranse uns contra outros nunha nova guerra civil interna. Se gaña a esquerda, loitarán comunistas e socialistas contra anarquistas. Se gaña a dereita o enfrontamento será entre republicanos moderados á portuguesa e reaccionarios estilo carlista" 24 .

En calquera caso, o que Madariaga vía necesario era que Inglaterra -é dicir, Eden, como ministro de Exteriores-, actuase. Formúlao con notable insistencia, subliñando literalmente as expresións de urxencia: "a política correcta agora é buscar a mediación", Gran Bretaña debe adoptar unha "política activa”, "creo que deberías tomar a iniciativa canto antes", "Inglaterra é a única potencia que podería facelo"..., son expresións coas que premeu unha e outra vez para que os británicos se decidisen a romper a postura de "benévola neutralidade" 25 que adoptaran dende o principio.

\footnotetext{
${ }^{20}$ Madariaga a Eden, 18.VIII.1936, Documento 1.

${ }^{21}$ Madariaga a Eden, 30.XII.1936, Documento 7.

${ }^{22}$ Xa que a súa premisa inicial era que ningún dos dous bandos podía gañar: "The war is a fiftyfifty affair and no side can win" (Madariaga a Eden, 18.VIII.1936, Documento 1).

${ }^{23}$ Madariaga a Eden, 18.VIII.1936, Documento 1.

${ }^{24}$ Madariaga a Eden, 18.VIII.1936, Documento 1.

${ }^{25}$ Por usar o título co que define esa postura Enrique MORADIELLOS, Neutralidad benévola. El Gobierno británico y la insurrección militar española de 1936, Oviedo 1990.
} 
As súas presións non serviron de gran cousa. A pesar das rápidas e afectuosas respostas de Eden, case sempre recibiu longas aos seus urxentes chamamentos. Así foi dende a primeira proposta, que o ministro acolleu "con simpatía" pero que consideraba, dille, "un asunto no que hai que entrar con pés de chumbo o que, lamentablemente, impide unha respostas inmediata" 26 . De feito, no que estiveron de acordo dende o principio, e así faillo ver Cranborne, foi en que

"o mellor e, de feito, o único posible a xeito de prolegómeno vai pola liña humanitaria. A parte da súa proposta que se refire a este tipo de mediación coincide craramente coa nosa postura" 27 .

A partir de aí xa non houbo moito máis avance. Esa postura coincide coa actuación británica ao longo da guerra: favorecer a colaboración coa Cruz Vermella, posibilitar o intercambio de prisioneiros, facilitar barcos que permitisen a evacuación non só de británicos senón tamén de españois ameazados ou refuxiados noutras embaixadas, etc., Máis alá da acción humanitaria non parece haber futuro. As propostas de Madariaga non deixaban de ser vistas como imposibles, se non inxenuas, por parte de Eden. E iso aínda que en reunións diplomáticas utilizase a información e as mesmas palabras de Madariaga ${ }^{28}$.

As cartas que recollemos son especialmente significativas da formulación dun liberal nos primeiros meses da guerra civil. E as respostas -cordialmente evasivas- de Eden ás formulacións tan idealistas como irreais de Madariaga, reflicten tamén a postura da diplomacia británica. Non hai que perder de vista que Eden foi un antinazi convencido, pouco proclive ás posturas a favor da pacificación, que o levaron a dimitir en protesta pola débil actitude inglesa ante Hitler. Non obstante, na súa correspondencia durante a guerra, dá a impresión que tanto el coma os seus colaboradores, consideraban irreais as propostas de mediación de Madariaga. Dende un punto de vista realista, como era o do Foreing Office británico, nin había posibilidade de negociar unha paz que non quería ningún dos bandos enfrontados, nin moito menos, poderíase chegar a

${ }^{26}$ Eden a Madariaga, 20.VIII.1936, Documento 2.

${ }^{27}$ Cranborne a Madariaga, 3.IX.1936, Documento 4.

28 "El 20 de agosto, el embajador español [López Oliván] habló en tonos sombríos de la situación de su país. Estaba de acuerdo con la opinión que me había expresado recientemente el señor de Madariaga y que le repetí, de que, dejando a un lado la intervención extranjera, los dos bandos estaban tan igualados que ninguno podía ganar. Compartía también la opinión de Madariaga de que aquella guerra no era de libertad y democracia contra la tiranía, pues ninguno de los dos bandos podía decirse que representase la democracia y la libertad" (EDEN, Anthony, Memorias 1923-1938, Barcelona 1962, p. 530). É, literalmente, o mesmo que lle escribía Madariaga. 
conseguir un futuro pacífico dentro de España sen que fose liquidada unha das partes enfrontadas.

Nas cartas que transcribimos recóllese unicamente a correspondencia do ano 1936, que remata coa última carta de Madariaga a Eden xa dende Estados Unidos. Aínda que aquí só incluímos esa primeira correspondencia Madariaga-Eden, os seus intentos por lograr algún tipo de mediación foron constantes ao longo do conflito, practicamente ata o final, sempre sen éxito. Dalgún modo, o idealismo de Madariaga e a súa distancia do realismo diplomático queda reflectida na insinuación de involucrar a Gandhi nas negociacións a favor da paz, ao tempo que confesaba a súa incapacidade para xuntar as vontades dos españois contendentes. En calquera caso, neste 70 aniversario do fin da guerra paga a pena recoller estes textos que manifestan, polo menos, a súa obsesión, como a doutros españois do momento, para deter dende fóra unha guerra que xa resultaba imparable dende dentro.

\section{ANEXO. \\ CORRESPONDENCIA ENTRE SALVADOR DE MADARIAGA E ANTHONY EDEN EN 1936}

\section{Documento 1}

Carta de Salvador de Madariaga a Anthony Eden desde Ginebra planteando su visión de la guerra civil y sugiriendo la conveniencia de añadir a la política de no-intervención otras acciones positivas a favor de la mediación. 18.VIII.1936.

Instituto José Cornide de Estudios Coruñeses

Archivo Salvador de Madariaga

Caja 127, C-7 $29,1936,1937,1938$

\section{Copia mecanografiada ${ }^{30}$}

Geneva, August 18th. 1936 31

PRIVATE AND CONFIDENTIAL

\footnotetext{
${ }^{29}$ Manteño a sinatura que figura no catálogo impreso aínda que na carpeta do arquivo figura coma carpeta 8. Probablemente xuntáronse con posterioridade dúas carpetas nunha.

30 Consérvase tamén o borrador mecanografado da carta.

${ }^{31}$ Manuscrito posto a data no momento de clarificar o documento: "Dudi to Eden". Dudi era o nome co que o chamaba de neno o seu neto Cristóbal, que foi probablemente quen fixo esta primeira clasificación xunto con Isabel de Madariaga. Agradezco o dato a María Jesús Garea, secretaria do Instituto José Cornide de Estudios Coruñeses, que amablemente o preguntou á propia Isabel de Madariaga.
} 
My dear Eden,

I am extremely anxious about the Spanish situation and I believe that the right policy now (I do not criticise that which has been done so far, which has been excellent) is no longer one of non intervention in war but one of intervention for peace. These are my reasons:

1. The war is a fifty-fifty affair and no side can win.

2. It is not a war of legality against illegality for ever since the last general election the two or three important elements within the Frente Popular which are indifferent to the Constitution or even inimical to it have carried out a highhanded and bullying policy which the Liberal-democratic Government has proved unable to repress -thereby explaining, though by no means justifying, the military rebellion. Such extraConstitutional policy has of course been greatly developed since the rebellion broke out.

3. It is not a war of liberty and democracy against tyranny because though the Government is sincerely liberal-democratic, it is controlled by socialists, communists and above all anarcho-syndicalists who deliberately aim at regimes in various ways incompatible with liberty and democracy, so that neither side can be said to represent democracy or liberty.

4. Both sides are hopelessly mixed an therefore if and when any of they feels relieved of the pressure of its adversary, another civil war is most likely - if the Left wins, between socialists and communists on the one side and syndicalists on the other, if the right wins, between moderate republicans a la portugaise and reactionnaries a la carliste. // anthony eden, private and confidential 2

5. Humanitarian reasons demand the end of this terrible bloodshed.

6. Though at present, neither party would in all likelihood be ready to listen to peace proposals, the situation will soon change if there is no outside interference in favour of one or other of the parties because without outside help neither side can win and they will soon realise it. From the point of view of Europe:

1. Through a tragic misreading of the situation the Spanish civil what is being identified with the issue Fascism v. communism and this may lead to a general European war.

2. A pact of non intervention in the war is bound to produce mistrust as to sincerity of its actual application by this or that power, while a pact of positive collaboration for peace is automatically controlled and its appeal would be more difficult to resist or to be treated by dilatory means.

3. The Spanish situation falls strictly under par. 2 of art. 11 of the League and though, owing to Germany, Geneva may not be the best procedure to deal with it, a country committed to the League, such as Great Britain must either apply art. 11 or pursue some other active policy. 
I realise that you might find the same reluctance in the powers which are now holding up the French proposal. I believe that it can be proved to those powers that they miscalculate the situation from the point of view of their national interests, because:

a. A militaristic-clerical regime would be unstable and live under a perpetual threat

b. The foreign policy of Spain will always be dictated by inmutable laws both of geo-political character and of national psychology which all regimes, no matter their preferences, will be found to follow.

I believe you should take the initiative in this. No power but England can do it. I have definite views as to the outline of a // anthony eden, private and confidential 3 proposal which might be put before both parties after the four powers were agreed on a common policy to back it with their combined moral so strength, but I would prefer to leave the details for a later stage. All I wish to say is that I am ready to cooperate with you in this endeavour and to go to London or anywhere else, see you or anyone else that may be necessary. I have excellent relations with some of the people that we would have to persuade. I am here at your disposal. Though so far as I am personally concerned, I fear nothing, I believe the utmost discretion is necessary so that the scheme does not fail through premature discussion and I think the less I am know to handle it the better. You might communicate with me (address and phone below) either through your Consul here or through my friend Monsieur Dussaq, Maison Royale, Quai Gustave Ador, Geneva, always under a double envelope. I am sending this also by a devious route.

I hope I may be able to hear from you as soon possible. Time be ripe for your intervention quite soon.

\section{Documento 2}

Carta de Anthony Eden a Salvador de Madariaga contestando la del 18 de agosto. 20.VIII.1936.

Instituto José Cornide de Estudios Coruñeses

Archivo Salvador de Madariaga

Caja 127, C-7, 1936, 1937, 1938

\section{Original mecanografiado}

[Membrete:] Sello del Foreing Office

FOREING OFFICE S.W.1

August 20th, 1936.

My dear de Madariaga ${ }^{32}$

\footnotetext{
${ }^{32}$ Manuscrito.
} 
Thank you very much for your letter of August 18th regarding the position in Spain. I can assure you that I have every sympathy with your feelings and am most deeply concerned at the present very grave situation in your country. The whole question is under constant consideration here and I will have the suggestion which you put forward examined without delay. The matter will, however require to be gone into very carefully and it is really not possible, I am afraid, for me to return an immediate reply to your proposals.

You may rest assured, however, that I am fully alive to the dangers of the existing situation and will do my utmost to facilitate a solution of the present difficulties.

I see our mutual friend Olivan nearly every day and I am sure that he appreciates the truth of what I have written ${ }^{33}$.

[Firmado:] Anthony Eden

Senor de Madariaga

\section{Documento 3}

Carta de Salvador de Madariaga a Anthony Eden desde Ginebra adjuntando un informe sobre la situación española e insistiendo en su preocupación por la necesidad de aplicar fórmulas de mediación. 24.VIII.1936.

Instituto José Cornide de Estudios Coruñeses

Archivo Salvador de Madariaga

Caja 127, C-7, 1936, 1937, 1938

\section{Copia mecanografiada}

Geneva, August 24 th 1936

Dear Eden,

I hear you miss my definitive proposals. I have been working at them in my mind. They are not, as you surely guess, easy to put together. The enclosed paper is the best I can do. I meant to send them through O. but his trip to Paris and the fact he has not called me since, the desirability of not delaying any longer, and my own patience, decide me to let you have them direct. You may use them as you used the letter with our common friend. You both know that I do not in the least wish to be indiscreet or to "butt in". I will do -or not do- whatever you think best. Incidentally, when in my previous letter I mentioned my good relations with people which might need conversion, I did not refer to my countrymen. I dont think I could be any good that way. I was referring to a few private friendships, such as Ghandi etc.

Ever

6 rue Pré Naville. ${ }^{34}$

\footnotetext{
${ }^{33}$ Manuscrito. Julio López Olivar, monárquico pero embaixador de España ata fins de agosto, precisamente, cando a República o sustituir por Pablo de Azcárate.

${ }^{34}$ Manuscrito engadido ao clsificarse o documento: "No paper enclosed".
} 


\section{Documento 4}

Carta de Robert Gascoyne-Cecil, subsecretario de Asuntos Exteriores, respondiendo las del 24 y 31 de agosto en nombre de Anthony Eden, que se encontraba enfermo. 18.VIII.1936.

Instituto José Cornide de Estudios Coruñeses

Archivo Salvador de Madariaga

Caja 127, C-7, 1936, 1937, 1938

\section{Original mecanografiado}

No. W 10351/62/41

Foreing Office, S.W.1

3rd September, 1936

Dear Madariaga, ${ }^{35}$

The Secretary of State, who is ill, has asked me to thank you for your further letters of the 24 and 31st August in which you develop your proposals for mediation in the Spanish conflict. Eden has read these with great interest and hopes that they may be useful at a large stage.

The Secretary of State was interested to see that you are in agreement with us that the best and indeed the only method of preliminary approach is on humanitarian lines. The part of your proposal which deals with this type of mediation is in surprisingly close agreement with what we are already attempting.

Tours sincerely ${ }^{36}$

[Firmado:] Cranborne ${ }^{37}$

Senor de Madariaga ${ }^{38}$

35 Manuscrito.

37 Robert Gascoyne-Cecil (1893-1972), vizconde de Cranborne e, posteriormente, marqués de Salisbury, subsecretario de Asuntos Exteriores, estreito colaborador de Eden. Nun importante mitin electoral, celebrado o 25 de febreiro de 1938, Eden recordou a estreita conexión que tivo con Lord Cranborne: "Entonces, -di nas súas memorias- aproveché la oportunidad de rendir homenaje a lord Cranborne: «Durante los dos años últimos como subsecretario, y durante mucho más tiempo en un aspecto menos oficial, lord Cranborne me ha prestado una ayuda inestimable en el Foreign Office. No es exagerado decir que sin su cooperación el peso del trabajo habría resultado intolerable. Nunca podré expresar debidamente lo que han representado para mi su consejo, paciencia, valor e inflexible sentido del deber. En lo que el futuro pueda depararnos a algunos de nosotros no cabe duda que lord Cranborne esta destinado a desempeñar un papel mucho más importante en los asuntos nacionales durante los años venideros»" EDEN, Anthony, Memorias 1923-1938, p. 789.

${ }^{38}$ Manuscrito engandido a pé de páxina: "Letter of 31 August from D[udi] to Eden missing. 


\section{Documento 5}

Carta de Salvador de Madariaga a Anthony Eden desde Londres adjuntando documentación, proponiendo que los laboristas presionen a Largo Caballero para que acepte negociar con Franco y urgiendo a Eden a tomar alguna determinación mediadora. 6.XI.1936.

Instituto José Cornide de Estudios Coruñeses

Archivo Salvador de Madariaga

Caja 127, C-7, 1936, 1937, 1938

\section{Copia mecanografiada}

21, Hampstead Hill Gardens

NW3

Nov. 6th.

My dear Eden,

The enclosed papers reaches me from quarters which are more extreme left than left, Spanish, bien entendu. As you will see, it confirms many of the assumptions and reproduces many of the suggestions of my letters to you. It seems to me that the time has come for some action -possibly not exactli the action therein suggested, possibly not with the same results. But I believe that the British Labour people ought to do some thing to persuade Largo Caballero to get out of the picture and that an action near Burgos by British diplomacy might have excellent results for Spain and perhaps no less excellent results for Great Britain.

As I am leaving next week (Nov. 14th) for USA and in any case could be of no use of the further development of this business, I do not offer any more detailed suggestions but feel confident that you will realise the urgency of the action to taken and the opportunity which would be missed if at the precise moment, which I take it to be right now, something was not done in the general direction outlined in this paper. I am communicating the paper, though not this letter, to my friend Dalton.

Yours cordially, (nota) manuscrito de quen clasificou a carta: "No paper enclosed".

\section{Documento 6}

Carta de Anthony Eden a Salvador de Madariaga agradeciéndole el envío del 6 de noviembre. 13.XI.1936.

Instituto José Cornide de Estudios Coruñeses

Archivo Salvador de Madariaga

Caja 127, C-7, 1936, 1937, 1938

\section{Copia mecanografiada}

Foreing Office. S.W.1.

November 13th, 1936 
My dear de Madariaga, ${ }^{39}$

Many thanks for your letter of the 6th November, and the paper on the political situation in Spain enclosed therein.

I have read them with interest and am going into the points which they raise $\mathrm{e}^{40}$.

His Excellency

Señor de Madariaga

\section{Documento 7}

Carta de Salvador de Madariaga a Anthony Eden planteando la conveniencia de involucrar a Alemania en las negociaciones y proponiendo una comisión negociadora formada por Besteiro, Alba y Martínez Barrio, todos ellos presidentes de las Cortes republicanas. 30.XII.1936.

Instituto José Cornide de Estudios Coruñeses

Archivo Salvador de Madariaga

Caja 127, C-7, 1936, 1937, 1938

\section{Copia mecanografiada}

500 Fifth Avenue,

New York, N.Y.

December 30, 1936

My dear Eden:

Just a few bits of information and one or two reflections on my subjet which is uppermost in my mind.

On the German side I gather first that any attempt at solving the problem by bringing them in at a later stage than the others would be resented to the point of erecting a new and unnecessary obstacle on the road to mediation. You may, perhaps, think that they are entitled to as early consideration as the other and on the same footing. I also gather that, while accepting the scheme as a whole, they express some doubts as to the possibility of obtaining military obedience of the foreign chiefs contemplated. This point would, therefore, have to be carefully gone into.

On the anti-German side, the objection is raised that it is impossible to reach an agreement with the two dictators on any point. I believe that those who think so overlook the fact that up till now there has not been on the international field any concrete action on which the interests of the four nations concerned were in harmony. However objectionable in themselves dictators do not differs at all from

\footnotetext{
39 Manuscrito.

${ }^{40}$ Liña final manuscrita desexándolle unha feliz viaxe e os mellores desexos.
} 
other governments of indeed from any individual in his senses in that we all define agreement on the aim to be achieved rather than the persons to achieve it with. You know how strongly I feel that the stopping of the war in Spain may be successively proved to be in the immediate national interest of very one of the powers, which are now in different ways meddling with it.

Nor would I be deterred by the difficulties encountered in Berlin, Rome and Lisbon by the Anglo-French proposal about volunteers for it is evident to me that such difficulties are due to the fact that the question of help to one or other of the parties to the civil war cannot be separated at all from that of the stopping of the war, nor therefore from that of the outcome of the war. These three questions are only three sides of the same question. You cannot expect the German government to drop Franco altogether without their knowing who is going to govern Spain when Franco is dropped and the war is over. That is why it seems to me negotiations for non-intervention, mediation and future organisation of Spain must be carried out simultaneously so far as possible.

It occurred to me the other day that an idea which may be aired as for the commission of government which is to take over // 2 at the armistice is the following: The commission to be compose of the three presidents which the republican Cortes have so far had. This would give a democratic flavour to the commission which would please our friend brethren and, on the other and, would produce a body fairly well balanced from the point of view of political tendencies, to wit

Besteiro, the president of the first Cortes, a socialist, highly respected though the head of the moderate section of the party. This circumstance has kept him out of office for the last three years. He is, therefore, the only prominent socialist which, from the other side, stands clean of all responsability.

Alba (not the Duke), president of the second Cortes, an ex-foreign secretary of the king who became member of the radical republican (Lerroux's) party. He would be the extreme right of the commission. His name would be a guarantee to capital and property an yet, even from his monarchical days he is know to be powerfully interested in the agrarian reform.

Martínez Barrio, the president of the present Cortes, who may therefore be considered as a member of the present government. He is the head of one of the two bourgeous parties in the present government and he would hold the middle from the point of view of political tendencies in governing commission.

I hope you like this idea which appeals to me as much better in quality than the usual stuff that comes into my head. 